\section{Inflammation, new bone formation and treatment options in axial spondyloarthritis}

\author{
Joachim Sieper, Denis Poddubnyy
}

How and whether ankylosis is connected with inflammation has been discussed for a long time. ${ }^{1}$ There are two major reasons for this debate. First, no effective antiinflammatory treatment was available in the past for ankylosing spondylitis (AS) as salicylates, which have been used to treat inflammatory rheumatic diseases for over 100 years, were not effective. However, the first non-steroidal anti-inflammatory drug (NSAID), phenylbutazone, was introduced into clinical practice around 1949 and was highly effective in patients with active AS. It was followed in subsequent decades by many other NSAIDs. The good therapeutic efficacy of NSAIDs was used to differentiate AS from degenerative causes of back pain ${ }^{2}$ due to their good anti-inflammatory properties. Nonetheless, NSAIDs for the treatment of AS are still often regarded incorrectly by the public as just 'painkillers' which should be avoided. ${ }^{3}$ Furthermore, conventional anti-inflammatory diseasemodifying anti-rheumatic drugs (DMARDs) which are highly effective in many chronic rheumatic diseases such as rheumatoid arthritis, are not effective in $\mathrm{AS},{ }^{4}$ similarly to low or moderate doses of glucocorticoids, which also show lack of efficacy. ${ }^{5}$ All this contributed to the assumption that inflammation does not play a major role in AS, which was believed to be rather dominated by new bone formation and ankylosis.

Approximately 14 years ago, the dramatic efficacy of tumour necrosis factor (TNF) blockers was demonstrated in patients with active AS. ${ }^{6}$ The debate on the interaction between inflammation and new bone formation was fuelled again by the finding that treatment of patients with active AS with TNF blockers for 2 years, despite the good effect on signs and symptoms, C-reactive protein (CRP) and inflammation as detected by MRI, did not prevent new bone formation in the spine. ${ }^{7}$ This is the second major reason

Medical Department I, Rheumatology, Campus Benjamin Franklin, Charité, Berlin, Germany

Correspondence to Professor Joachim Sieper, Medical Department I, Rheumatology, Campus Benjamin Franklin, Charité, Hindenburgdamm 30, 12200 Berlin, Germany; joachim.sieper@charite.de for the ongoing discussion on the association between inflammation and new bone formation in AS.

Two main hypotheses have been put forward to explain a certain dissociation between inflammation and new bone formation. The first one claims that the development of spondyloarthritis (SpA) depends on a multi-step process that leads both to chronic or recurrent inflammation and to the triggering of new tissue formation, completely or partially independently of inflammation. ${ }^{8}$ The second one postulates that inflammation induces replacement of subchondral bone marrow by (fibrous) repair tissue which then stimulates osteoblasts, leading to new bone formation. ${ }^{9}$ Thus, based on the second hypothesis, early anti-inflammatory intervention should prevent new bone formation, while such an effect would not occur if the first hypothesis is correct. Various articles in recent years have argued in favour or against one of these hypotheses. $^{9-12}$

A relationship between inflammation and structural damage in early AS (symptom duration <10 years) was reported recently for the first time based on an analysis of the prospective GErman SPondyloarthritis Inception Cohort (GESPIC). Elevated CRP at baseline was clearly associated with progression of structural damage of the sacroiliac joints, ${ }^{13}$ based on X-ray analysis, but even more importantly in the context of the current discussion, elevated CRP was also associated with osteoproliferative progression in the spine over 2 years. ${ }^{14}$ In this analysis, disease activity parameters such as the Bath Ankylosing Spondylitis Disease Activity Index (BASDAI), which is purely based on patient-reported outcome (PRO) parameters, were not found to be associated with radiographic progression of the spine. The influence of the Ankylosing Spondylitis Disease Activity Score (ASDAS), which combines PROs with CRP, was not analysed in this study.

Attempts have also been made to correlate active inflammatory changes on MRI (subchondral bone marrow oedema) with the occurrence of structural damage on follow-up, both for sacroiliac joints ${ }^{15}$ and the spine, ${ }^{16}$ although such an association was found to be rather weak. ${ }^{17}$ This might be explained by the fact that bony inflammation seen on MRI can be short and/or fluctuating but might be sufficient to induce replacement of subchondral bone marrow by repair tissue. This is probably best visible as fatty lesions on an MRI T1 sequence. Indeed, the presence of fatty lesions or a combination of fatty lesions plus inflammation at baseline was the strongest predictor of radiographic spinal progression in several studies. ${ }^{18} 19$

In the landmark study presented by Ramiro et $a l^{20}$ it was shown for the first time that clinical parameters of disease activity also correlate with radiographic progression in AS. By using a longitudinal, auto-regressive model with 2-year time lags in AS patients from the OASIS cohort followed up to 12 years, it could be shown that the ASDAS was the strongest predictor of radiographic progression, even better than CRP alone, the BASDAI alone or a combination of the BASDAI and CRP. But interestingly, an association could also be shown for a purely PRO parameter such as the BASDAI. Thus, these data indicate that a longitudinal analysis is more powerful for the detection of an association between disease activity and radiographic progression in AS than cross-sectional analyses, as was already shown previously for rheumatoid arthritis. $^{21}$

Based on this study ${ }^{20}$ and on the earlier report showing a correlation between elevated CRP and radiographic progression, ${ }^{14}$ we now have clear evidence that inflammation and new bone formation are related in AS. The current model even allows such a relationship to be quantified, with an increase of 1 ASDAS unit leading to an increase of $0.72 \mathrm{mSASSS}$ units/2 years, an estimation which might also be useful for daily clinical practice. However, it is less clear whether the real relationship between ASDAS and the modified Stoke Ankylosing Spondylitis Spinal Score (mSASSS) is actually linear. Furthermore, the reported progression rate should be regarded as a 'mean' value in the entire population as individual progression rates as a result of ASDAS increase may vary. Indeed, the current study also shows that there is still, although slower, radiographic progression even in patients with inactive disease, with an mSASSS increase of 5 points on average over 12 years in this subgroup. How can this be explained? In the analysed OASIS study, the mean disease duration was rather long at 20 years. $^{20}$ Thus, structural damage already present would 
lead to new or further bone formation over time, independent of the presence of inflammation. ${ }^{18}$ The relatively long disease duration in the OASIS cohort can be seen as a limitation of this study, since it is unclear whether an ASDAS increase has a similar effect on radiographic progression at an earlier stage of the disease. Furthermore, because only $30 \%$ of the patients in this study were female, no clear conclusion is possible about radiographic progression in women. However, the limited data indicate that there is no or less correlation between parameters of activity and radiographic progression in women.

The relationship between different parameters of diseases activity such as PROs (eg, the BASDAI), CRP and MRI inflammation is rather weak. ${ }^{22}{ }^{23}$ We have only recently reported that such correlation is best early in the course of the disease, ${ }^{24}$ indicating that patients' symptoms are not only caused by inflammation in the long term. The rather poor correlation also suggests that it is difficult to measure disease activity using single domains. The combined score for PROs and CRP (the ASDAS) has proven to be rather powerful in clinical studies to discriminate best between TNF blockers and placebo. $^{25}$ Based on the best correlation between an elevated score and radiographic progression in the current study, compared to other parameters, the ASDAS seems to reflect disease activity best. This should be confirmed in other cohorts, especially in those with shorter symptom duration, ${ }^{14}$ also because the ASDAS/radiographic progression correlation was best in patients with shorter symptom duration ( $<18$ years) in this AS population with long-standing disease.

The effect of elevated disease activity on new bone formation shown here is a big advance in understanding this rather complex relationship and is also potentially important for future treatment strategies in axial $\mathrm{SpA}$, including the 'treat to target' approach. ${ }^{26}$ However, it has to be shown in therapeutic studies that lowering disease activity effectively can indeed retard radiographic progression in AS. As shown before, treatment over 2 years ${ }^{7}$ or even 4 years ${ }^{27}$ does not seem to be sufficient, but treatment with a TNF blocker for more than 4 years slowed down new bone formation in the spine in longstanding AS compared to a historical control group in one study. ${ }^{28}$ Alternatively, early treatment before the manifestation of irreversible structural damage might also slow down radiographic progression, as was reported recently based on an analysis from a prospective AS cohort. $^{29}$ Long-term treatment studies in patients with early axial $\mathrm{SpA}$, including those with non-radiographic axial SpA before structural damage is visible on $\mathrm{X}$-ray, are now possible based on the new ASAS classification criteria for axial SpA. ${ }^{30}$ In light of the current evidence, we would hypothesise that early treatment of axial SpA with a TNF blocker might retard radiographic progression, but that in long-standing AS a combination with another drug inhibiting new bone formation might be necessary. As some evidence indicates that NSAIDs might be able to inhibit radiographic progression, ${ }^{31}$ a clinical trial investigating the effect of combination therapy of a TNF blocker with an NSAID would be of interest.

Contributors Both authors contributed to the writing of this editorial.

\section{Competing interests None.}

Provenance and peer review Commissioned; externally peer reviewed.

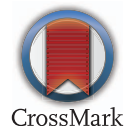

To cite Sieper J, Poddubnyy D. Ann Rheum Dis 2014;73:1439-1441.

Received 24 March 2014

Accepted 17 April 2014

Published Online First 8 May 2014

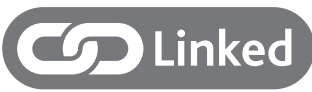

- http://dx.doi.org/10.1136/annrheumdis-2014205178

Ann Rheum Dis 2014:73:1439-1441.

doi:10.1136/annrheumdis-2014-205464

\section{REFERENCES}

1 Sieper J, Braun J, Rudwaleit M, et al. Ankylosing spondylitis: an overview. Ann Rheum Dis 2002;61 (Suppl 3):iiiz-18.

2 Amor B, Dougados M, Listrat $\mathrm{V}$, et al. [Evaluation of the Amor criteria for spondylarthropathies and European Spondylarthropathy Study Group (ESSG). A cross-sectional analysis of 2228 patients]. Ann Med Interne (Paris) 1991:142:85-9.

3 Song $\mathrm{IH}$, Poddubnyy DA, Rudwaleit $\mathrm{M}$, et al. Benefits and risks of ankylosing spondylitis treatment with nonsteroidal antiinflammatory drugs. Arthritis Rheum 2008:58:929-38

4 Braun J, van den Berg R, Baraliakos X, et al. 2010 update of the ASAS/EULAR recommendations for the management of ankylosing spondylitis. Ann Rheum Dis 2011;70:896-904.

5 Haibel H, Fendler C, Listing J, et al. Efficacy of oral prednisolone in active ankylosing spondylitis: results of a double-blind, randomised, placebo-controlled short-term trial. Ann Rheum Dis 2014;73:243-6.

6 Brandt J, Haibel H, Cornely D, et al. Successful treatment of active ankylosing spondylitis with the anti-tumor necrosis factor alpha monoclonal antibody infliximab. Arthritis Rheum 2000:43:1346-52.
7 van der Heijde D, Landewe R, Baraliakos X, et al. Radiographic findings following two years of infliximab therapy in patients with ankylosing spondylitis. Arthritis Rheum 2008;58:3063-70.

8 Lories RJ, Luyten FP, de Vlam K. Progress in spondylarthritis. Mechanisms of new bone formation in spondyloarthritis. Arthritis Res Ther 2009;11:221.

9 Sieper J, Appel H, Braun J, et al. Critical appraisal of assessment of structural damage in ankylosing spondylitis: implications for treatment outcomes. Arthritis Rheum 2008;58:649-56.

10 Maksymowych WP, Elewaut D, Schett G. Motion for debate: the development of ankylosis in ankylosing spondylitis is largely dependent on inflammation. Arthritis Rheum 2012;64:1713-19.

11 Maksymowych WP, Morency N, Conner-Spady B, et al. Suppression of inflammation and effects on new bone formation in ankylosing spondylitis: evidence for a window of opportunity in disease modification. Ann Rheum Dis 2013;72:23-8.

12 Lories $\mathrm{R}$. The balance of tissue repair and remodeling in chronic arthritis. Nat Rev Rheumatol 2011;7:700-7.

13 Poddubnyy D, Rudwaleit M, Haibel H, et al. Rates and predictors of radiographic sacroilititis progression over 2 years in patients with axial spondyloarthritis. Ann Rheum Dis 2011;70:1369-74.

14 Poddubnyy D, Haibel H, Listing J, et al. Baseline radiographic damage, elevated acute-phase reactant levels, and cigarette smoking status predict spinal radiographic progression in early axial spondylarthritis. Arthritis Rheum 2012;64:1388-98.

15 Bennett AN, McGonagle D, O'Connor P, et al. Severity of baseline magnetic resonance imaging-evident sacroiliitis and HLA-B27 status in early inflammatory back pain predict radiographically evident ankylosing spondylitis at eight years. Arthritis Rheum 2008;58:3413-18.

16 Maksymowych WP, Chiowchanwisawakit P, Clare T, et al. Inflammatory lesions of the spine on magnetic resonance imaging predict the development of new syndesmophytes in ankylosing spondylitis: evidence of a relationship between inflammation and new bone formation. Arthritis Rheum 2009;60:93-102.

17 van der Heijde D, Machado P, Braun J, et al. MRI inflammation at the vertebral unit only marginally predicts new syndesmophyte formation: a multilevel analysis in patients with ankylosing spondylitis. Ann Rheum Dis 2012;71:369-73.

18 Chiowchanwisawakit P, Lambert RG,

Conner-Spady B, et al. Focal fat lesions at vertebral corners on magnetic resonance imaging predict the development of new syndesmophytes in ankylosing spondylitis. Arthritis Rheum 2011;63:2215-25

19 Baraliakos X, Heldmann F, Callhoff J, et al. Which spinal lesions are associated with new bone formation in patients with ankylosing spondylitis treated with anti-TNF agents? A long-term observational study using MRI and conventional radiography. Ann Rheum Dis 2013. Published Online First 14 Jul 2013. doi:10.1136/annrheumdis-2013203425

20 Ramiro S, Van der Heijde D, van Tubergen A, et al. Higher disease activity leads to more structural damage in the spine in ankylosing spondylitis: 12-year longitudinal data from the OASIS cohort. Ann Rheum Dis 2014;73:1455-61.

21 Welsing PM, Landewe RB, van Riel PL, et al. The relationship between disease activity and radiologic progression in patients with rheumatoid arthritis: a longitudinal analysis. Arthritis Rheum 2004;50:2082-93.

22 Kiltz U, Baraliakos $X$, Karakostas $\mathrm{P}$, et al. The degree of spinal inflammation is similar in patients with axial spondyloarthritis who report high or low levels of disease activity: a cohort study. Ann Rheum Dis 2012:71:1207-11.

23 Machado P, Landewe RB, Braun J, et al. MRI inflammation and its relation with measures of 
clinical disease activity and different treatment responses in patients with ankylosing spondylitis treated with a tumour necrosis factor inhibitor. Ann Rheum Dis 2012;71:2002-5.

24 Weiss $\mathrm{A}$, Song IH, Haibel H, et al. Good correlation between changes in objective and subjective signs of inflammation in short- but not long-diseased patients with axial spondyloarthritis treated with tumor necrosis factor-blockers. Arthritis Res Ther 2014; 16:R35.

25 van der Heijde D, Lie E, Kvien TK, et al. ASDAS, a highly discriminatory ASAS-endorsed disease activity score in patients with ankylosing spondylitis. Ann Rheum Dis 2009;68:1811-18.
26 Smolen JS, Braun J, Dougados M, et al. Treating spondyloarthritis, including ankylosing spondylitis and psoriatic arthritis, to target: recommendations of an international task force. Ann Rheum Dis 2014;73:6-16.

27 Braun J, Baraliakos $X$, Hermann KG, et al. The effect of two golimumab doses on radiographic progression in ankylosing spondylitis: results through 4 years of the GO-RAISE trial. Ann Rheum Dis 2014;73:1107-13.

28 Baraliakos X, Haibel H, Listing J, et al. Continuous long-term anti-TNF therapy does not lead to an increase in the rate of new bone formation over 8 years in patients with ankylosing spondylitis. Ann Rheum Dis 2014;73:710-15.
29 Haroon N, Inman RD, Learch TJ, et al. The impact of tumor necrosis factor alpha inhibitors on radiographic progression in ankylosing spondylitis. Arthritis Rheum 2013;65:2645-54.

30 Rudwaleit $\mathrm{M}$, van der Heijde $\mathrm{D}$, Landewe $\mathrm{R}$, et al. The development of Assessment of SpondyloArthritis international Society classification criteria for axial spondyloarthritis (part II): validation and final selection. Ann Rheum Dis 2009;68:777-83.

31 Kroon $F$, Landewe $R$, Dougados $M$, et al. Continuous NSAID use reverts the effects of inflammation on radiographic progression in patients with ankylosing spondylitis. Ann Rheum Dis 2012;71:1623-9. 